\title{
Phenotypes and genotypes in individuals with SMC1A variants
}

Sylvia Huisman ${ }^{1,2}$

Anne-Marie Bisgaard ${ }^{6}$

Dinah Clark ${ }^{10}$

\section{Valerie Cormier-Daire ${ }^{11}$}

Egbert Redeker $^{4}$ | Ingrid Bader ${ }^{5}$ |

\section{Anna Cereda ${ }^{8}$ | Constanza Cinca ${ }^{9}$ |}

Karin Diderich $^{7}$ | Mariet Elting ${ }^{13}$ | Anthonie van Essen ${ }^{\dagger}$ | David Fitz Patrick ${ }^{14}$ |

Cristina Gervasini $^{15}$ | Gabriele Gillessen-Kaesbach ${ }^{16}$ | Katta M. Girisha ${ }^{17}$ (i) |

Yvonne Hilhorst-Hofstee $^{18}$ | Saskia Hopman ${ }^{19}$ | Denise Horn ${ }^{20}$ | Mala Isrie ${ }^{13}$

Sandra Jansen $^{21}$ | Cathrine Jespersgaard ${ }^{6}$ | Frank J. Kaiser ${ }^{22}$ | Maninder Kaur ${ }^{10}$

Tjitske Kleefstra $^{21}$ | Ian D. Krantz ${ }^{10,12}$ | Phillis Lakeman ${ }^{4}$ | Annemiek Landlust ${ }^{3}$ |

Davor Lessel $^{23}$ (i) | Caroline Michot ${ }^{11}$ | Jo Moss ${ }^{24,25}$ (i) | Sarah E. Noon ${ }^{10}$ |

Chris Oliver ${ }^{24}$ | Ilaria Parenti ${ }^{16,22}$ | Juan Pie ${ }^{26}$ | Feliciano J. Ramos ${ }^{27}$ |

Claudine Rieubland $^{28}$ | Silvia Russo ${ }^{29}$ | Angelo Selicorni ${ }^{30}$ | Zeynep Tümer ${ }^{6}$ |

Rieneke Vorstenbosch $^{31}$ | Tara L. Wenger ${ }^{32}$ | Ingrid van Balkom ${ }^{3}$ |

Sigrid Piening $^{3}$ | Jolanta Wierzba ${ }^{33}$ | Raoul C. Hennekam ${ }^{1}$

\footnotetext{
${ }^{1}$ Department of Pediatrics, Academic Medical Center, University of Amsterdam, Amsterdam, the Netherlands

2 Prinsenstichting Institute, Purmerend, the Netherlands

${ }^{3}$ Autism Team Northern-Netherlands, Jonx Department of Youth Mental Health and Autism, Lentis Psychiatric Institute, Groningen, the Netherlands

${ }^{4}$ Department of Clinical Genetics, Academic Medical Center, University of Amsterdam, Amsterdam, the Netherlands

${ }^{5}$ Division of Clinical Genetics, Department of Pediatrics, Paracelsus Medical University Salzburg, Salzburg, Austria

${ }^{6}$ Kennedy Center, Department of Clinical Genetics, Copenhagen University Hospital, Rigshospitalet, Glostrup, Denmark

${ }^{7}$ Department of Clinical Genetics, Erasmus Medical Center, Rotterdam, the Netherlands

8 Department of Pediatrics, ASST Papa Giovanni XXIII, Bergamo, Italy

9 División Genetica, Hospital de Clínicas José de San Martín, Universidad de Buenos Aires, Buenos Aires, Argentina

${ }^{10}$ Division of Genetics, Children's Hospital of Philadelphia, Philadelphia, Pennsylvania

${ }^{11}$ Department of Medical Genetics, Reference Center for Skeletal Dysplasia, INSERM UMR 1163, Laboratory of Molecular and Physiopathological Bases of Osteochondrodysplasia, Paris Descartes-Sorbonne Paris Cité University, AP-HP, Institut Imagine, and Hôpital Universitaire Necker-Enfants Malades, Paris, France

12 Department of Pediatrics, Perelman School of Medicine, University of Pennsylvania, Philadelphia, Pennsylvania

${ }^{13}$ Department of Clinical Genetics, VU University Medical Center, Amsterdam, the Netherlands

${ }^{14}$ MRC Human Genetics Unit, IGMM, Western General Hospital, Edinburgh, United Kingdom

${ }^{15}$ Department of Health Sciences, Medical Genetics, University of Milan, Milan, Italy

${ }^{16}$ Institut für Humangenetik Lübeck, Universitätsklinikum Schleswig-Holstein, Lübeck, Germany

17 Department of Medical Genetics, Kasturba Medical College, Manipal University, Manipal, India

${ }^{18}$ Department of Clinical Genetics, Leiden University Medical Centre, Leiden, the Netherlands

${ }^{19}$ Department of Genetics, University Medical Center Utrecht, Utrecht, the Netherlands

20 Institut für Medizinische Genetik und Humangenetik, Berlin, Germany
}

${ }^{\dagger}$ (Deceased) Department of Genetics, University Medical Center Groningen,

University of Groningen, Groningen, the Netherlands. 
${ }^{21}$ Department of Human Genetics, Donders Centre for Neuroscience, Radboud University Medical Center, Nijmegen, the Netherlands

22 Section for Functional Genetics, Institute of Human Genetics, University of Lübeck, Lübeck, Germany

23 Institute of Human Genetics, University Medical Center Hamburg-Eppendorf, Hamburg, Germany

${ }^{24}$ Cerebra Centre for Neurodevelopmental Disorders, School of Psychology, University of Birmingham, Birmingham, United Kingdom

25 Institute of Cognitive Neuroscience, University College London, London, United Kingdom

${ }^{26}$ Laboratorio de Genética Clínica y Genómica Funcional, Facultad de Medicina, Universidad de Zaragoza, Zaragoza, Spain

27 Unidad de Genética Clínica, Servicio de Pediatría, Hospital Clínico Universitario "Lozano Blesa” CIBERER-GCV02 and Departamento de Pediatría, Facultad de Medicina, Universidad de Zaragoza, Zaragoza, Spain

${ }^{28}$ Division of Human Genetics, Department of Pediatrics, Inselspital, Bern University Hospital, University of Bern, Bern, Switzerland

29 Molecular Biology Laboratory, Istituto Auxologico Italiano, Milan, Italy

30 UOC Pediatria, ASST Lariana, Como, Italy

31 Severinus Institute, Veldhoven, the Netherlands

32 Division of Craniofacial Medicine, Seattle Children's Hospital, Seattle, Washington

${ }^{33}$ Departments of Pediatrics, Hematology, Oncology and Department of General Nursery, Medical University of Gdansk, Gdansk, Poland

\section{Correspondence}

Sylvia Huisman, MD, Department of Pediatrics, H7-228, Academic Medical Center, Meibergdreef 9, 1105AZ Amsterdam, the Netherlands.

Email: s.a.huisman@amc.uva.nl

\section{Funding information}

National Institutes of Health, Grant number: UMO-2014/15/B/NZ5/03503; Spanish Ministry of Health - ISCIII; Fondo de Investigación Sanitaria (FIS), Grant number: Ref: PI15/00707; Diputación General de Aragón (Grupo Consolidado B20); European Social Fund ("Construyendo Europa desde Aragón"); German Federal Ministry of Education and Research (BMBF, CHROMATIN-Net)
SMC1A encodes one of the proteins of the cohesin complex. SMC1A variants are known to cause a phenotype resembling Cornelia de Lange syndrome (CdLS). Exome sequencing has allowed recognizing SMC1A variants in individuals with encephalopathy with epilepsy who do not resemble CdLS. We performed an international, interdisciplinary study on 51 individuals with SMC1A variants for physical and behavioral characteristics, and compare results to those in 67 individuals with NIPBL variants. For the Netherlands all known individuals with SMC1A variants were studied, both with and without CdLS phenotype. Individuals with SMC1A variants can resemble CdLS, but manifestations are less marked compared to individuals with NIPBL variants: growth is less disturbed, facial signs are less marked (except for periocular signs and thin upper vermillion), there are no major limb anomalies, and they have a higher level of cognitive and adaptive functioning. Self-injurious behavior is more frequent and more severe in the NIPBL group. In the Dutch group 5 of 13 individuals (all females) had a phenotype that shows a remarkable resemblance to Rett syndrome: epileptic encephalopathy, severe or profound intellectual disability, stereotypic movements, and (in some) regression. Their missense, nonsense, and frameshift mutations are evenly spread over the gene. We conclude that SMC1A variants can result in a phenotype resembling CdLS and a phenotype resembling Rett syndrome. Resemblances between the SMC1A group and the NIPBL group suggest that a disturbed cohesin function contributes to the phenotype, but differences between these groups may also be explained by other underlying mechanisms such as moonlighting of the cohesin genes.

\section{KEYWORDS}

behavior, Brachmann-De Lange syndrome, Cornelia de Lange syndrome, NIPBL, Rett syndrome, self-injurious behavior, severity score, SMC1A, syndrome delineation

\section{1 | INTRODUCTION}

"Doctor, really wonderful that you have found that our boy has a SMC1A mutation! But please, what does that mean for him, and what can we expect?" In an era dominated by diagnostic tests using microarrays and exome sequencing that identify gene variants, this is in fact a major question that patients and their families like to be answered. This manuscript tries to provide some first answers to that question.

The first clinical reports on SMC1A described that variants in this gene cause $\mathrm{X}$-linked Cornelia de Lange syndrome or a mild variant of Cornelia de Lange syndrome (CdLS) (Borck et al., 2007; Deardorff et al., 2007; Musio et al., 2006). CdLS is a multisystem disorder characterized by intrauterine growth retardation, short stature, typical face, congenital anomalies of especially the distal upper limbs, and intellectual and developmental disabilities. Behavioral characteristics include autism spectrum disorder, and a predisposition to engage with challenging behavior, especially self-injurious behavior (SIB) (Huisman et al., in press, 2017; Moss, Howlin, Magiati, \& Oliver, 2012; Mulder et al., 2016; Oliver, Sloneem, Hall, \& Arron, 2009). CdLS is associated with variants in a series of genes; variants in NIPBL ( 70-75\%) and SMC1A ( 5\%) are the most prevalent (Bhuiyan et al., 2006; Huisman, Redeker, Maas, Mannens, \& Hennekam, 2013; Krantz et al., 2004; Tonkin, Wang, Lisgo, Bamshad, \& Strachan, 2004).

The CdLS phenotype caused by SMC1A variants overlaps with the phenotype in individuals with NIPBL variants. Individuals with SMC1A 
variants were first reported with less marked facial features, less effects on growth, and without limb reduction defects (Borck et al., 2007; Deardorff et al., 2007; Musio et al., 2006). Subsequent publications have reported on a more variable phenotype (Ansari et al., 2014; Basel-Vanagaite et al., 2016; Chatfield et al., 2012; Gervasini et al., 2013; Hoppman-Chaney, Jang, Jen, BabovicVuksanovic, \& Hodge, 2012; Limongelli et al., 2010; Liu, Feldman, et al., 2009; Liu Zhang et al., 2009; Mannini, Liu, Krantz, \& Musio, 2010; Parenti et al., 2014; Pie et al., 2010, 2016; Rohatgi et al., 2010; Yuan et al., 2015). Through the use of panel screening aimed at identifying variants in genes linked to intellectual disability, and the use of untargeted trio exome analysis, SMC1A variants are increasingly detected in individuals in whom CdLS was not clinically suspected. In some of these patients the main manifestation is an epileptic encephalopathy (de Ligt et al., 2012; Fieremans et al., 2016; Gilissen et al., 2014; Goldstein et al., 2015; Hansen, Mohr, Burki, \& Lemke, 2013; Jang, Lee, Kim, \& Ki, 2015; Jansen et al., 2016; Lebrun et al., 2015; Tzschach et al., 2015; Wenger et al., 2016).

This urged us to initiate an interdisciplinary study in a relatively large series of individuals with a confirmed SMC1A mutation. We aimed to gather data on their physical and behavioral phenotype, and to compare the data to a series of individuals with CdLS in whom NIPBL variants were found (Bhuiyan et al., 2006; Yan et al., 2006). Here we report on the detailed results of the physical studies and on the results of the behavioral studies in general; detailed results of the behavioral studies will be published elsewhere (Mulder et al., 2016).

\section{2 | METHODS}

\subsection{Study design}

We performed a cross-sectional study in a large international series of individuals with pathological SMC1A variants, using in person evaluations in Dutch participants, and questionnaire results and clinical pictures in patients from other countries.

\section{2 | Dutch SMC1A cohort}

The molecular genetic laboratory of the Academic Medical Center in Amsterdam has been the central Dutch site to perform panel analysis to detect variants in any of the genes associated with CdLS, and SMC1A mutation analysis by Sanger sequencing. We contacted the physicians in charge of all individuals with pathological SMC1A variants, asking them to obtain permission for us to contact the family. Subsequently, we contacted all Dutch molecular laboratories that perform exome sequencing and asked whether they had detected additional SMC1A variants either using panel screening for intellectual disability/epilepsy or using untargeted trio analysis. Eleven families were contacted of which ten families (13 patients) agreed to participate in the study. After written consent, two authors (S.H.; R.C.H.) performed clinical evaluations (medical history, physical and morphological examination, clinical pictures) in 10 individuals and collected data from three individuals who had passed away. Two other authors (P.A.M.; A.L.) performed direct behavioral assessments (ADOS \& Bayley-III-NL/WPPSI-III-NL/WAIS-IV-NL) and interviews (SSP-NL and VABS-2) in eight of the remaining individuals (one had died in the meantime; one could not be contacted for further behavioral studies). In addition, we asked parents to fill out a set of behavioral questionnaires, which included the Repetitive Behavior Questionnaire (RBQ), Challenging Behavior Questionnaire (CBQ), and Gastroesophageal Reflux Questionnaire (GRQ).

\section{3 | International SMC1A cohort}

We invited the members of the Scientific Advisory Committee of the CdLS World Federation from Denmark, France, Germany, Italy, Poland, Portugal, Spain, Sweden, U.K., and U.S.A. to participate, requesting to identify individuals with pathological variants in their series, and to contact their molecular genetic laboratories to check for additional SMC1A variants. We forwarded a comprehensive, dedicated questionnaire on somatic characteristics (morphology, malformations, neurodevelopment, physical health; see Supplemental materials) to the physicians and requested to forward a set of behavioral questionnaires to the families.

\section{4 | NIPBL comparison group}

We collected data from the Polish CdLS database of individuals with NIPBL pathological variants $(n=43)$, some of whom were included in previous publications (Kuzniacka et al., 2013; Yan et al., 2006), and from a previously published Dutch cohort with NIPBL pathological variants $(n=24)$ (Bhuiyan et al., 2006). To both sets we added data that have become available since publications.

\section{5 | Severity score}

A severity score can be predictive of clinical course and maturation relative to other individuals affected by the same or related entity. Since Gillis et al. (2004) proposed the first severity classification system based on three CdLS phenotype parameters (limb reduction, cognitive abilities, and growth), the severity scoring system has been modified and refined (Bhuiyan et al., 2006; Kline et al., 2008). We used the classification system as suggested by Bhuiyan et al. (2006), as it includes all major CdLS parameters (facial morphology, limb anomalies, growth parameters [prenatal; postnatal; skull] and cognitive/adaptive level of abilities) in a standardized and non-interdependent manner.

\subsection{Statistics}

Data were stored in Excel format. Descriptive statistics and Chi square test were performed using Microsoft Excel version 2011. Behavioral data were converted from the questionnaires into a coded SPSS file and were analyzed using IBM SPSS Statistics version 23.

\section{7 | Ethics}

The present study has been supported by the national and international CdLS Support Groups, and approved by the Medical 
Ethics Committee of the Academic Medical Center in Amsterdam (NL39553.018.12).

\section{3 | RESULTS}

We collected data from 51 individuals with pathological SMC1A variants (36 missense, 15 other types). Participants originated from the Netherlands (13 [25\%]), USA (9 [18\%]), the UK (8 [16\%]), and smaller numbers from Argentina, Austria, Denmark, France, Germany, India, Italy, Spain, Switzerland, and Turkey. Somatic questionnaires were completed from all 51 participants. Behavioral questionnaires were obtained from 31 participants (response rate 60\%). Median age was 13 years (range: 0-46 years), gender ratio was $14 \mathrm{M}$ to $37 \mathrm{~F}$. Median age of clinical diagnoses was 5 years (range: 0-46 years), median age of last examination was 11 years (range: 0-40 years). Median age of the NIPBL group was 14 years (range: $0-46$ years), gender ratio was $34 \mathrm{M}$ to $33 \mathrm{~F}$.

\subsection{Physical phenotypes}

The faces of the Dutch patients are depicted in Figure 1. The main results of the present study are presented in Tables 1-4. The data in the SMC1A group are compared to the 67 individuals with NIPBL variants. The severity scores in CdLS-like, Rett-like, and NIPBL positive individuals is depicted in Figure 2 . In the text we only mention those data that are not presented in the tables.

The congenital cardiac malformations observed in individuals with SMC1A mutations consisted of pulmonic stenosis $(n=3)$, atrial septal defects $(n=3)$, persistent ductus arteriosus $(n=2)$, ventricular septal defect $(n=1)$, dextrocardia $(n=1)$, aortic coarctation $(n=1)$, pulmonary valve dysplasia $(n=1)$, and left ventricular noncompaction with apical hypertrophy $(n=1)$. Cryptorchidism was scored as a minor anomaly and was present in four of the 15 males (27\%) with SMC1A variants; $31 / 34$ males (91\%) with NIPBL variants had cryptorchidism. Early pubic hair development was reported in four females with a pathological SMC1A variant.

\section{2 | Milestones}

While tabulating the milestones we left out SMC1A positive children below 5 years of age who were still too young to score with certainty whether they would or would not acquire the milestone before the age of 5 years. If a child $\geq 5$ year old had not reached a milestone we indicated this.

\section{3 | Genotypes}

Of the present series half $(26 / 51)$ of patients have been published before. The nature and site of variants in the present series does not differ from those reported in literature (Table 5; Figure 3).

\section{4 | Reasons for molecular analysis}

In the Dutch cohort, 5/15 (38\%) of patients were clinically suspected of CdLS prior to molecular testing. For five patients CdLS was included in the differential diagnosis, but other diagnoses were thought to be more likely. For the remaining three patients CdLS was not clinically suspected at all. All patients coming from other countries were clinically suspected to
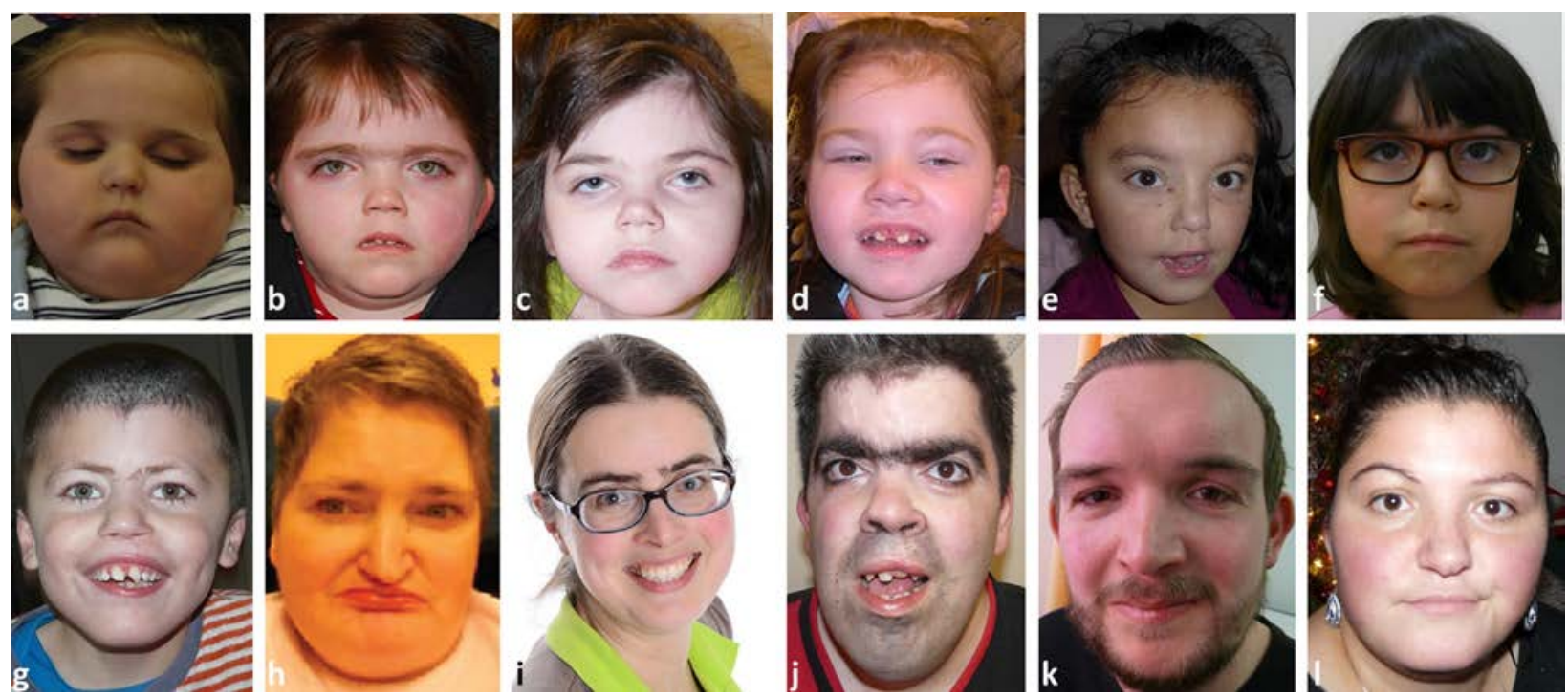

FIGURE 1 Faces of individuals with SMC1A variants from the Dutch cohort. a. SMC1ANL007, b. SMC1ANL001, c. SMC1ANL002, d. SMC1ANL008, e. SMC1ANL015, f. SMC1ANL003, g. SMC1ANL004, h. SMC1ANL011, i. SMC1ANL009, j. SMC1ANL005, k. SMC1ANL006, I. SMC1ANL014. Note resemblances especially between faces depicted in A-D. Patient SMC1ANL014 (I) and SMC1ANL015 (e) are mother and daughter. Form a detailed description of facial morphology please see Table 1 and text. [Color figure can be viewed at wileyonlinelibrary.com] 
TABLE 1 General overview of the phenotype in individuals with SMC1A variants subdivided by types, compared to those with NIPBL variants reported in a Dutch and Polish cohort

\begin{tabular}{|c|c|c|c|c|}
\hline & All $n=51$ & Missense variants $n=36$ & Other variants $n=15$ & NIPBL literature $n=67$ \\
\hline Gender (M/F) & $14(27) / 37(73)$ & $11(31) / 25(69)$ & $3(20) / 12(80)$ & $34(51) / 33(49)$ \\
\hline \multicolumn{5}{|l|}{ Growth } \\
\hline Length at birth $<-2 S D$ & $9 / 32(28)$ & 6/21 (29) & $3 / 11(27)$ & $32 / 43(74)$ \\
\hline Weight at birth $<-2 S D$ & $11 / 41(27)$ & $8 / 27(30)$ & $3 / 14(21)$ & $29 / 43(67)$ \\
\hline Height $<-2 S D$ & $24 / 38(63)$ & $17 / 27(63)$ & $7 / 11(64)$ & $37 / 43(86)$ \\
\hline Weight $<-2$ SD & $14 / 37(38)$ & $11 / 26(42)$ & $3 / 11(27)$ & $39 / 43(91)$ \\
\hline Head circumference $<-2 S D$ & $23 / 36(64)$ & $18 / 26(69)$ & $5 / 10(50)$ & $54 / 62(87)$ \\
\hline \multicolumn{5}{|l|}{ Craniofacial morphology } \\
\hline Synophrys & $37 / 46(80)$ & 29/33 (88) & $8 / 13(62)$ & $61 / 67(91)$ \\
\hline Long eyelashes & $38 / 45(84)$ & $27 / 32(84)$ & $11 / 13(85)$ & $65 / 67(97)$ \\
\hline Depressed nasal bridge & $20 / 43(47)$ & $14 / 30(47)$ & $6 / 13(46)$ & $57 / 67(85)$ \\
\hline Anteverted nostrils & $26 / 46(57)$ & $21 / 33(64)$ & $5 / 13(38)$ & $58 / 67(87)$ \\
\hline Long, featureless philtrum ${ }^{c}$ & $27 / 43(63)$ & $20 / 30(67)$ & $7 / 13(54)$ & $54 / 67(81)$ \\
\hline Thin upper vermillion ${ }^{c}$ & $33 / 44(75)$ & $26 / 31(84)$ & $7 / 13(54)$ & $22 / 24(92)$ \\
\hline Downturned corners mouth & $33 / 46(72)$ & 24/33 (73) & $9 / 13(69)$ & $23 / 24(96)$ \\
\hline Palate (high arched; cleft) & 11/37 (30); 10/45 (22) & $8 / 26(31) ; 7 / 32(22)$ & $3 / 11$ (27); 3/13 (23) & $35 / 67(52) ; 20 / 67(30)$ \\
\hline Clinodactyly 5th finger & $21 / 45(47)$ & $17 / 32(53)$ & $4 / 13(31)$ & $42 / 63(67)$ \\
\hline Syndactyly & $1 / 37(3)$ & $1 / 26(4)$ & $0 / 11(0)$ & $4 / 63(6)$ \\
\hline Small feet & $29 / 44(66)$ & $20 / 31(65)$ & $9 / 13(69)$ & $65 / 67(97)$ \\
\hline Syndactyly 2 nd-3rd toes & $13 / 46(28)$ & $9 / 33(27)$ & $4 / 13(31)$ & $21 / 66(32)$ \\
\hline \multicolumn{5}{|l|}{ Skin } \\
\hline Cutis marmorata & $19 / 44(43)$ & $15 / 32(47)$ & 4/12 (33) & $27 / 43(63)$ \\
\hline Hirsutism & $37 / 47(79)$ & $28 / 34(82)$ & $9 / 13(69)$ & $37 / 43(86)$ \\
\hline \multicolumn{5}{|l|}{ Major and minor malformations } \\
\hline Limb (major) & $0 / 49(0)$ & $0 / 35(0)$ & $0 / 14(0)$ & $17 / 67(25)$ \\
\hline Heart (major and minor) & $13 / 44(30)$ & $10 / 32(31)$ & $3 / 12(25)$ & $18 / 66(27)$ \\
\hline Genitourinary system (major; minor) & 4/42 (10); $9 / 40(23)$ & $2 / 30(7) ; 7 / 29(24)$ & 2/12 (17); 2/11 (18) & $0 / 67(0) ; 46 / 67(69)$ \\
\hline Gut & $3 / 44(7)$ & $3 / 32(9)$ & $0 / 12(0)$ & $6 / 24(25)$ \\
\hline CNS & $5 / 43(12)$ & 4/31 (13) & $1 / 12$ (8) & \\
\hline
\end{tabular}

Percentages are shown in brackets.

Blank cell indicates that information was unavailable or uncertain.

${ }^{a}$ In three prematurely born individuals (between 31 and 35 weeks) growth data were corrected for a gestational age of 40 weeks.

${ }^{\mathrm{b}}$ Postnatal data are not available in one stillborn child.

${ }^{\mathrm{c}}$ In three patients this could not be reliably scored due to surgery for clefting.

dSeven of the others had such marked limb reduction defects that it prevented evaluation of hand size.

eMajor: uni/bilateral renal anomalies; minor: cryptorchidism; small penis; hypospadias; underdeveloped prepuce; small labia. 
TABLE 2 Natural history of physical, cognitive, and behavioral development in individuals with SMC1A variants subdivided by types, compared to those with NIPBL variants reported in a Dutch and Polish cohort

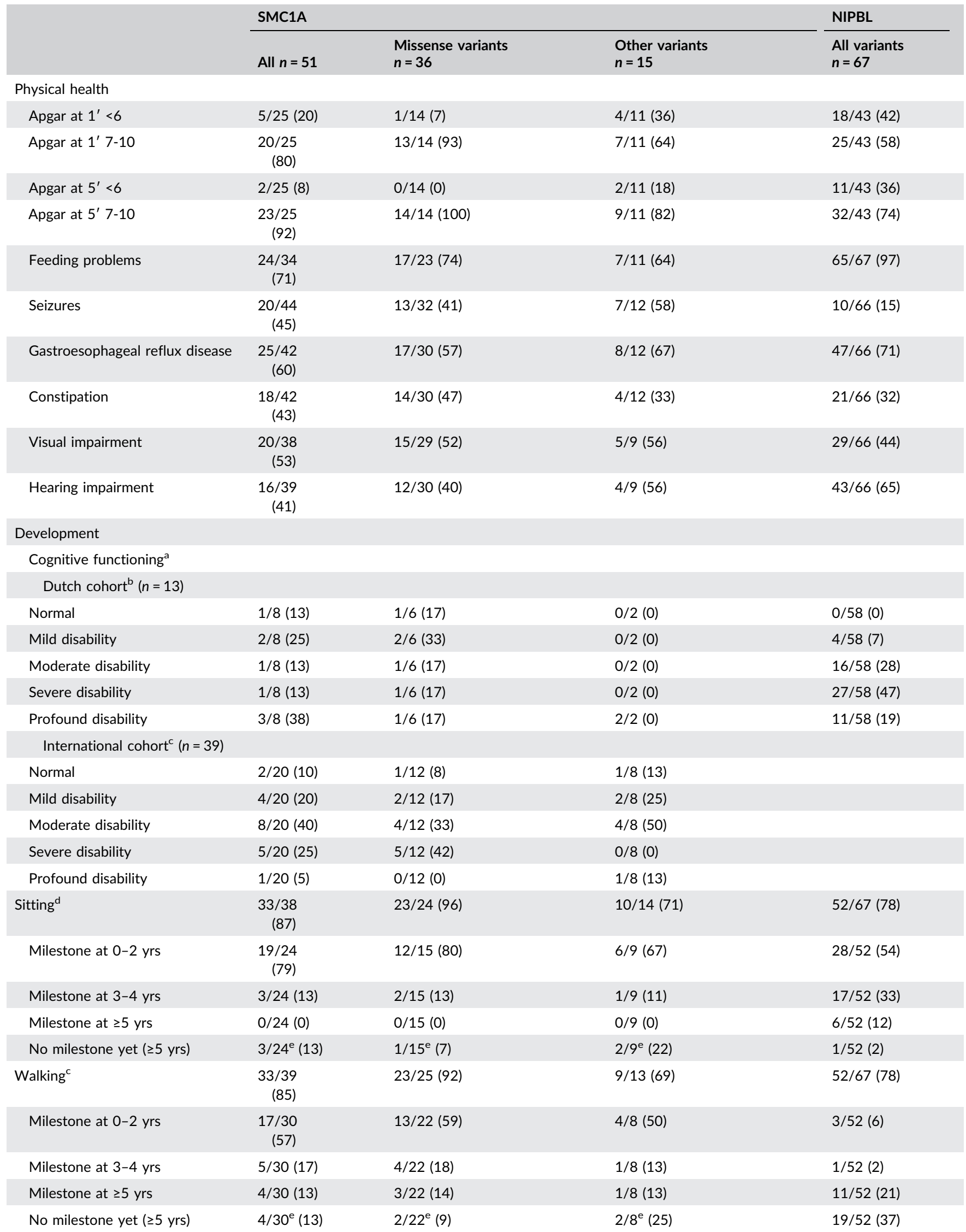


TABLE 2 (Continued)

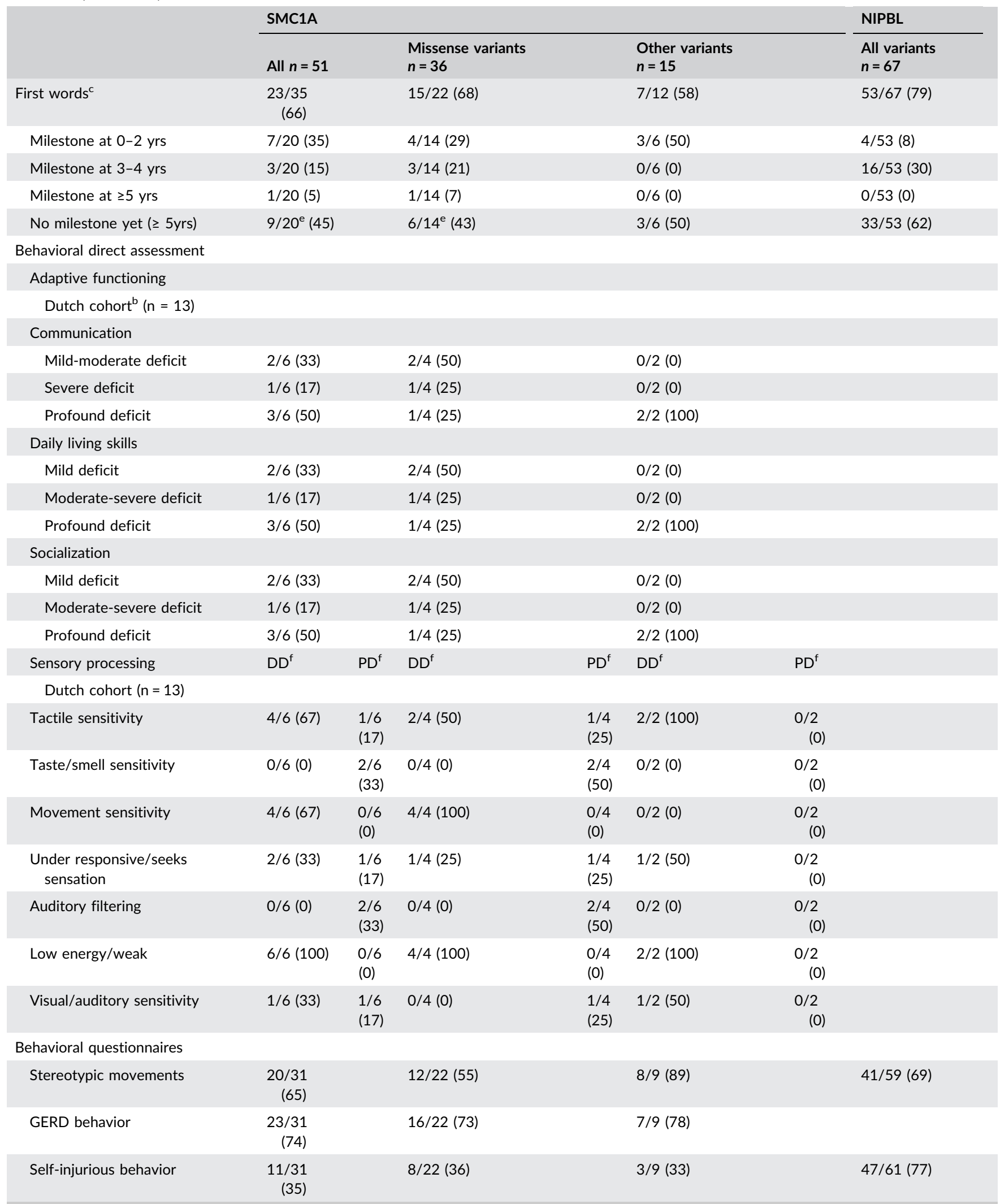

Percentages are shown in brackets.

Blank cells indicate that information was unavailable or uncertain.

${ }^{\mathrm{a} C}$ Classification based on DC-LD, WHO and DSM-5.

${ }^{\mathrm{b}}$ Based on validated testing by behavioral specialist.

${ }^{\mathrm{C}}$ Physician reported data, no validated testing data available.

${ }^{\mathrm{d}}$ Number of individuals (of total individuals of whom are data available) who has acquired this milestone during given period of age at the time of present study. 
eNumber of individuals (of total individuals of whom are data available) aged $\geq 5$ years who has not acquired this skill at time of present study. ${ }^{f} D D$, Definite Difference; PD, Probable Difference; some individuals could not be assessed on Taste/Smell sensitivity and/or Movement sensitivity due to PEG tube and not able to move independently.

have CdLS prior to molecular testing. The testing methods differed among patients depending on local laboratory protocols, and included Sanger sequencing, panel analysis aimed at genes associated with CdLS, and panel analysis aimed at genes associated with intellectual disability/epilepsy.

\section{4 | DISCUSSION}

SMC1A is known as a gene that can cause a cohesinopathy if mutated (Musio et al., 2006). The entities tagged as cohesinopathies have been considered overlapping entities (Liu \& Krantz, 2008). They share

TABLE 3 Severity scores in individuals with SMC1A variants subdivided by types compared to those with NIPBL variants reported in a Dutch and Polish cohort ${ }^{a}$

\begin{tabular}{|c|c|c|c|c|}
\hline & \multicolumn{3}{|l|}{ SMC1A } & \multirow{2}{*}{$\begin{array}{l}\text { NIPBL } \\
\text { All variants } n=67\end{array}$} \\
\hline & All $n=51$ & Missense variants $n=36$ & Other variants $n=15$ & \\
\hline \multicolumn{5}{|l|}{ Prenatal growth } \\
\hline $1500-2500 \mathrm{~g}$ & $15 / 41(37)$ & $11 / 28$ (39) & $4 / 13(31)$ & $37 / 63(59)$ \\
\hline$<1500 \mathrm{~g}$ & $0 / 41(0)$ & $0 / 28(0)$ & $0 / 13(0)$ & $11 / 63(17)$ \\
\hline$>$ P75 & $27 / 38(71)$ & $19 / 27(70)$ & $8 / 11(73)$ & $11 / 66(17)$ \\
\hline P25-P75 & $11 / 38(29)$ & $8 / 27(30)$ & $3 / 11(27)$ & $41 / 66(62)$ \\
\hline$<$ P25 & $0 / 38(0)$ & $0 / 27(0)$ & $0 / 11(0)$ & $14 / 66(21)$ \\
\hline \multicolumn{5}{|l|}{ Head growth } \\
\hline$>-2 S D$ & $15 / 37(40)$ & $10 / 27(37)$ & $5 / 10(50)$ & $6 / 66(9)$ \\
\hline No & $0 / 49(0)$ & $0 / 35(0)$ & $0 / 14(0)$ & $50 / 67(75)$ \\
\hline Partial & $0 / 49(0)$ & $0 / 35(0)$ & $0 / 14(0)$ & $4 / 67(6)$ \\
\hline Severe & $0 / 49(0)$ & $0 / 35(0)$ & $0 / 14(0)$ & $13 / 67$ (19) \\
\hline \multicolumn{5}{|l|}{ Face $^{d}$} \\
\hline Possible CdLS & $18 / 51(35)$ & $9 / 36(25)$ & $9 / 15(60)$ & $0 / 67(0)$ \\
\hline Mild & $24 / 51$ (47) & $18 / 36(50)$ & $6 / 15(40)$ & $10 / 67(15)$ \\
\hline Classical & $9 / 51(18)$ & $9 / 36(25)$ & $0 / 15(0)$ & $57 / 67(85)$ \\
\hline \multicolumn{5}{|l|}{ Intellectual disabilitye,f } \\
\hline
\end{tabular}

${ }^{a}$ Between brackets percentages for the characteristic within each (sub)group.

${ }^{\mathrm{b}} \mathrm{CdLS}$ standard growth curves were used for postnatal height.

${ }^{\mathrm{c}} \mathrm{No}=$ no reduction defect; partial = partial reduction defects (absence $1 / 2$ fingers); severe = severe reduction defects (absence 3 or more fingers or complicated oligo-/polydactyly).

${ }^{\mathrm{d}}$ Possible CdLS; mild = mild type; classical = classical type.

${ }^{\mathrm{e}}$ Classification based on DC-LD, WHO and DSM-5.

${ }^{f}$ Physician reported data, no validated testing data available.

${ }^{\mathrm{g}}$ Total severity score $=\Sigma$ (prenatal growth + postnatal growth + head growth + limb malformation + face + intellectual/adaptive functioning) $($ based on Bhuiyan et al., 2006). 


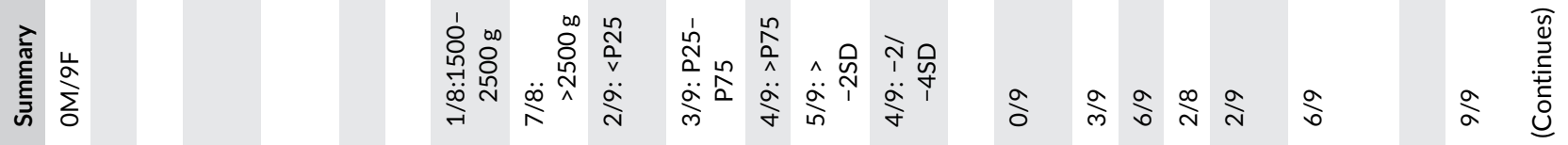

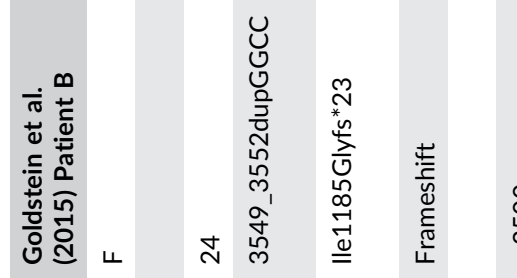

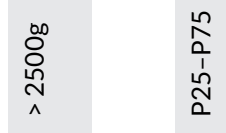

$\underset{\text { Nิ }}{0}$

蒿

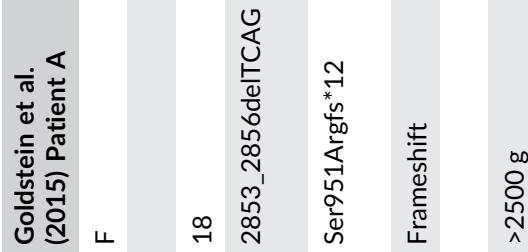

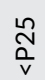

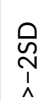

$\frac{0}{\frac{0}{\bar{n}}}$

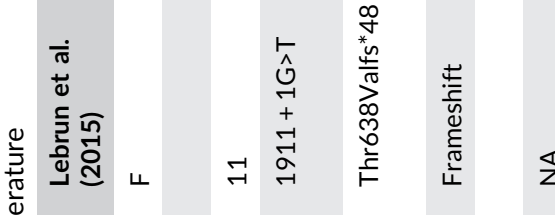

$\stackrel{\frac{1}{N}}{\stackrel{1}{n}}$

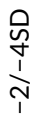

$\frac{0}{0}$
$\overline{\bar{W}}$
0
0

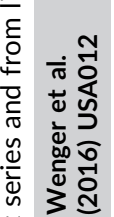

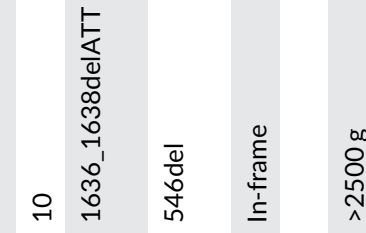

窇

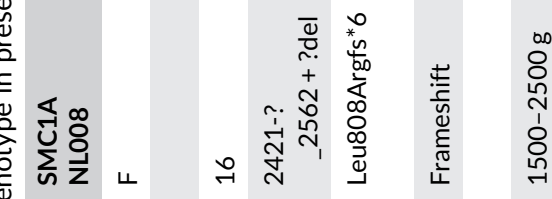

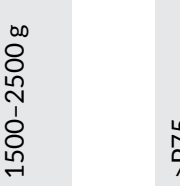

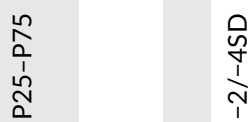

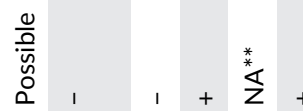

$\stackrel{n}{n}$

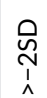

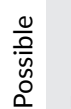

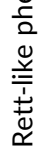

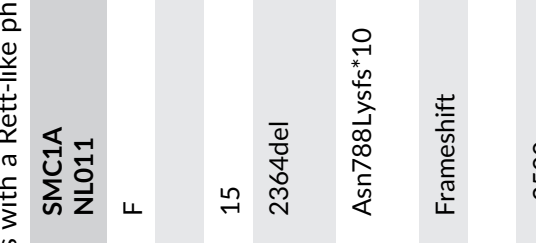

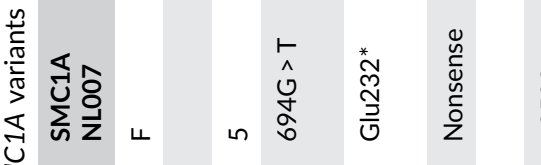

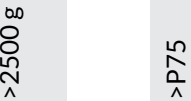

$\frac{0}{\frac{3}{1}}$

$\frac{0}{\frac{0}{\bar{n}}}$

$\sum_{n}^{i}$

喜

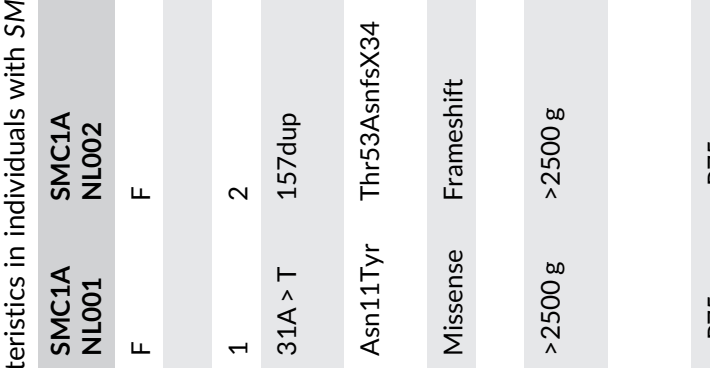

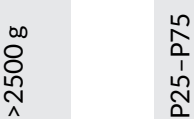

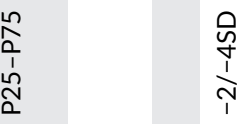

$\frac{0}{0}$
$\frac{0}{\bar{n}}$
0

$\frac{1}{n}$
$\frac{1}{n}$

$\frac{0}{0}$
$\frac{\bar{n}}{0}$
0

$\stackrel{\substack{n \\ n}}{n}$

$\stackrel{ }{\bar{\Sigma}}$

ป ป

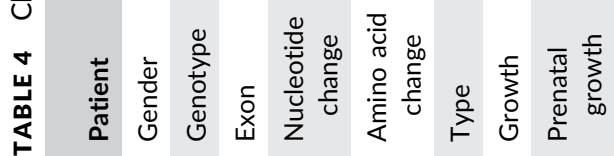

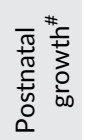

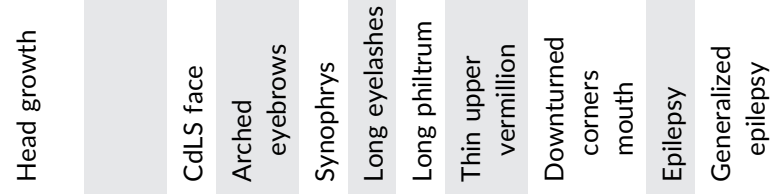



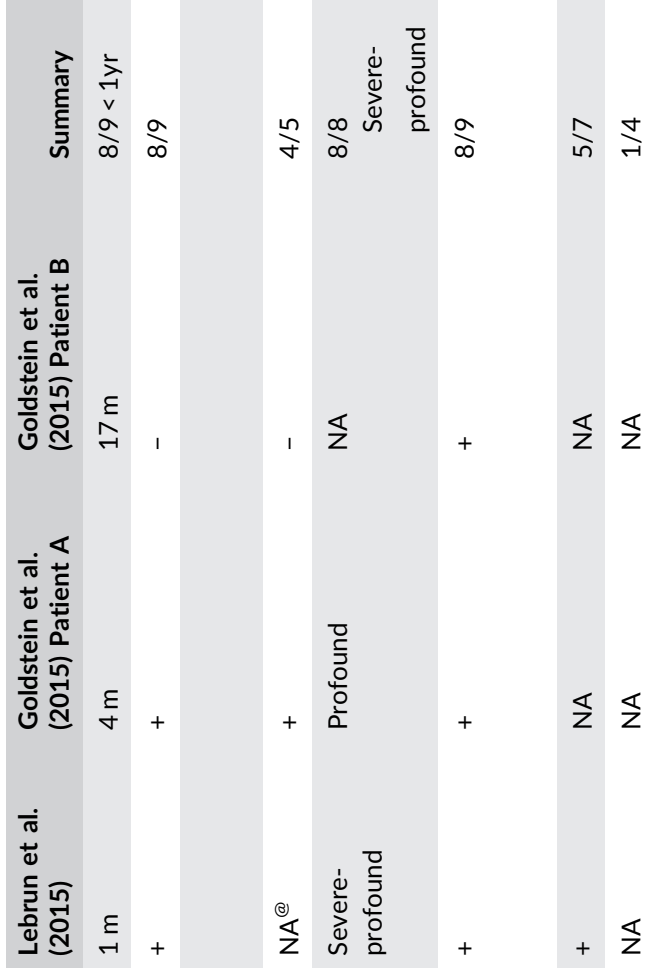

¿

$\mathbb{z} \frac{\pi}{z}$

กั

屯

\丶

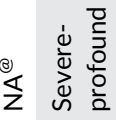

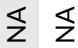

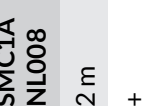

0
$\overline{0}$
$\frac{0}{0}$
$+\quad 0$

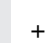

\section{जZ}

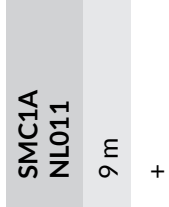

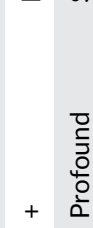

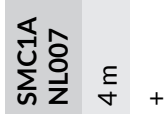

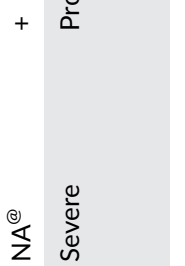

$+\stackrel{s}{z}$

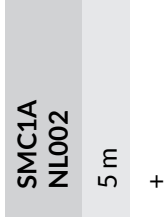

究审

ర్

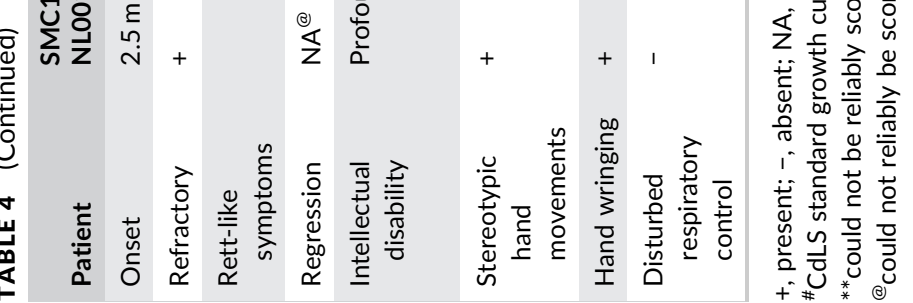




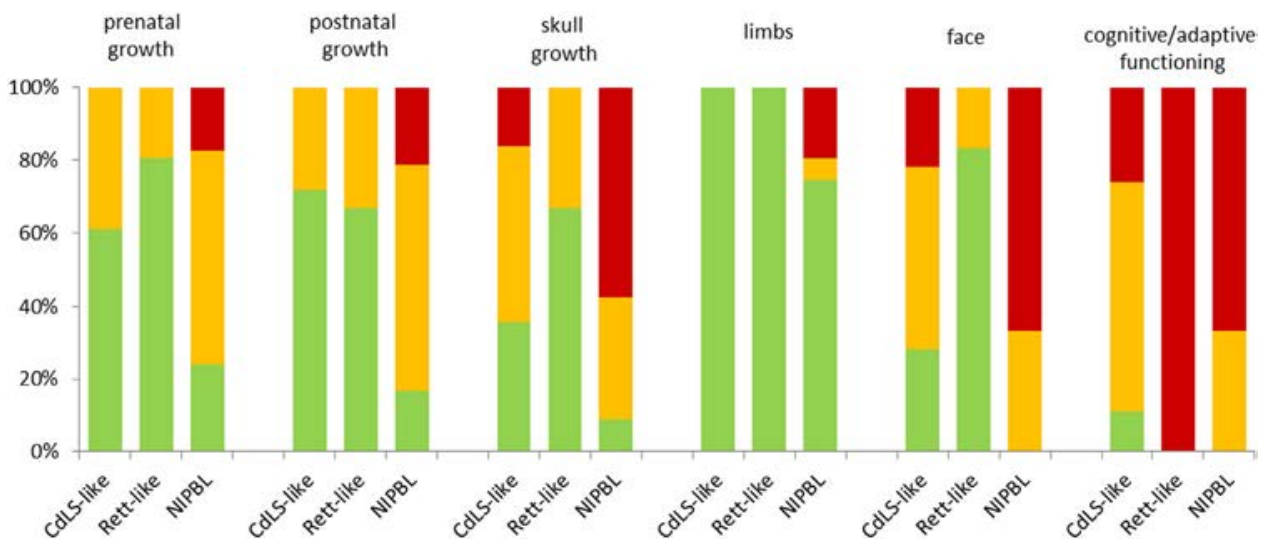

FIGURE 2 Histogram showing the total CdLS severity scores (Bhuiyan et al., 2006) in the presently reported SMC1A individuals with a CdLS-like phenotype versus those with a Rett-like phenotype and compared to literature patients with NIPBL variants. Green: lowest score for item; Yellow: middle score for item; Red: highest score for item. Note more severe growth impairment in NIBL group, absence of marked limb anomalies in the SMC1A groups, low resemblance of the Rett-like SMC1A subgroup to the CdLS-like subgroup and the NIPBL group, and less marked cognitive impairment in the CdLS-like SMC1A subgroup. [Color figure can be viewed at wileyonlinelibrary.com]

several physical and behavioral features, such as limited growth, several of the facial features, limb malformations, and intellectual disability. The cohesin complex and its regulators mediate sisterchromatid cohesion in dividing cells and are important for controlling gene expression (Remeseiro, Cuadrado, \& Losada, 2013). Sharing of major features of the cohesinopathies supports the hypothesis that a disturbed cohesin function contributes to these characteristics (Yuan et al., 2015). There are also differences in the phenotypes caused by SMC1A and NIPBL pathological variants. Such differences support the argument that the phenotype is not only a result of the disturbed cohesin function, but also a result of other functions (moonlighting) of the cohesin genes (Jeffery, 2014). One major difference in phenotype between the SMC1A and NIPBL group described here is the higher prevalence and more severe form of self-injurious behavior in the latter. The absence of this behavioral trait in patients with SMC1A variants with a Rett-like phenotype, and also in other cohesinopathies, such as individuals with CdLS due to variants in other genes and in individuals with Roberts syndrome (Vega et al., 2005), suggests a moonlighting hypothesis for NIPBL. Indeed knock-out mouse models for Nipbl have shown that Nipbl affects transcription and global dysregulation of gene expression, and consequently does have functions different from the cohesin function and have shown evidence for different polypeptide chain functions of NIPBL products and for expression changes in genes with roles in neuronal functions that underlie the behavioral and neurological abnormalities observed (Kawauchi et al., 2009, 2016).

Patients with cohesinopathies share several physical signs and symptoms that have been implicated as cause of SIB (Luzzani, Macchini, Valade, Milani, \& Selicorni, 2003), and this argues against the self-injurious behavior being secondary to these physical conditions. Therefore, further studies into cohesinopathies and their associated genes, should not only be aimed at the cohesin and related functions, but should also take into account other potential functions of these genes.
The higher incidence of SIB in the NIPBL group could be due to the cognitive level, since cognitive functioning is overall more affected in the NIPBL group than in the SMC1A group. However, SIB seems to be absent in the Rett-like group and yet cognitive functioning appears even lower. Further developmental testing may indicate other cognitive and behavioral differences that may contribute to this. An association (if any) between the results of cognitive and developmental assessments and SIB, and results of the behavioral studies should be described in much detail and will therefore be published elsewhere (Mulder et al., in preparation).

SMC1A variants are known to be associated with a CdLS phenotype. In comparing CdLS characteristics in the present study, the SMC1A group demonstrates a less disturbed growth compared to the NIPBL group. Prenatal growth parameters are below 2 SD in onethird of the SMC1A group, irrespective of the mutation type. In the NIPBL group prenatal growth parameters are below 2 SD in at least two-thirds of the group. Postnatal height and occipitofrontal circumference are decreased in two-thirds of the SMC1A group, which is less marked compared to the NIPBL group. However, weight is much more disturbed in the NIPBL group, possibly due to the much more frequent, more severe and more protracted feeding problems in this group.

All facial features that characterize CdLS can be present in individuals with SMC1A variants, but in a lower frequency compared to the NIPBL group. There are some exceptions: individuals with a missense SMC1A variant have the same frequency of periocular features as individuals in the NIPBL group, and also the prevalence of the thin upper vermillion is similar between the two groups. CdLS features that are more prevalent in the NIPBL group such as a small lower jaw and low-set and malformed ears occur more frequently in the group with a missense SMC1A mutation than in the group with other mutation types. However, the number of individuals in the latter group is small and results should be evaluated with care.

Limb reduction defects that are typical for CdLS and prevalent in $25 \%$ of the NIPBL group, are absent in the SMC1A group. Clinodactyly 
TABLE 5 Genotype in individuals with SMC1A variants from literature and in present series ${ }^{a}$

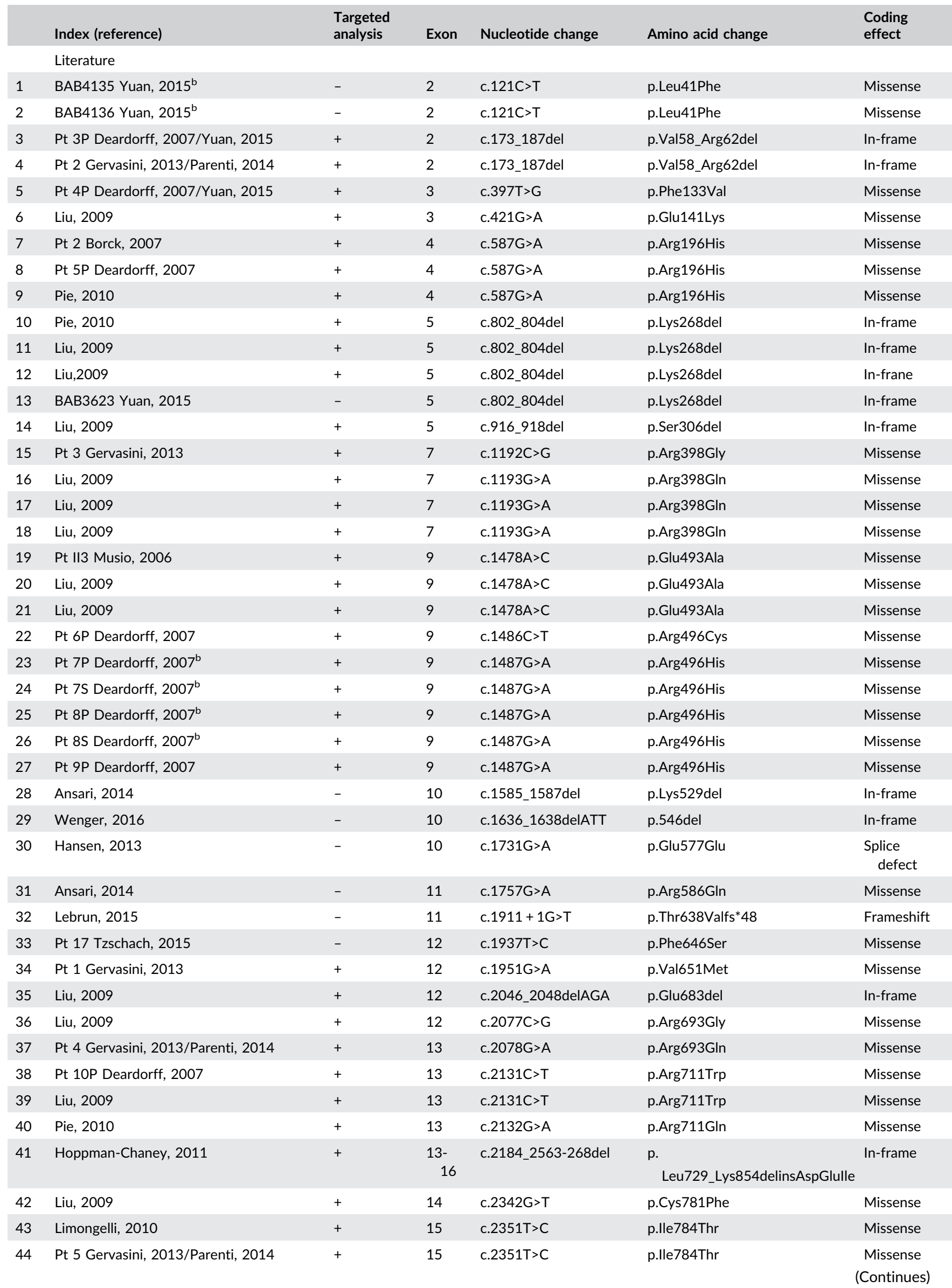


TABLE 5 (Continued)

\begin{tabular}{|c|c|c|c|c|c|c|}
\hline & Index (reference) & $\begin{array}{l}\text { Targeted } \\
\text { analysis }\end{array}$ & Exon & Nucleotide change & Amino acid change & $\begin{array}{l}\text { Coding } \\
\text { effect }\end{array}$ \\
\hline 45 & Pt 3 Fieremans, 2016 & - & 15 & c. $2351 \mathrm{~T}>\mathrm{C}$ & p.lle784Thr & Missense \\
\hline 47 & Ansari, 2014 & - & 15 & c. $2368 \mathrm{C}>\mathrm{T}$ & p.Arg790Trp & Missense \\
\hline 48 & Pt 11P Deardorff, 2007 & + & 15 & c. $2369 \mathrm{G}>\mathrm{A}$ & p.Arg790Gln & Missense \\
\hline 50 & Pt 6 Gervasini, 2013 & + & 15 & c. $2369 \mathrm{G}>\mathrm{A}$ & p.Arg790Gln & Missense \\
\hline 51 & $\begin{array}{l}\text { Pt } 98 \text { De Ligt, 2012/ Pt } 48 \text { Gillissen, } 2014 \\
\text { / Pt2 Jansen, } 2016\end{array}$ & - & $\begin{array}{l}16- \\
17\end{array}$ & c. $2421 \_2652 \mathrm{del}$ & p.Leu808Argfs*21 & Frameshift \\
\hline 52 & Liu, 2009 & + & 16 & c. $2446 C>G$ & p.Arg816Gly & Missense \\
\hline 53 & Mannini, 2010 & + & 16 & c. $2467 T>C$ & p.Phe823Leu & Missense \\
\hline 57 & Pt III4 Musio, 2006 /Parenti, 2014 & + & 16 & c.2493_2495del & p.Asp831_GIn832delinsGlu & In-frame \\
\hline 58 & Pt A Goldstein, 2015 & - & 18 & c.2853_2856delTCAG & p.Ser951Argfs*12 & Frameshift \\
\hline 59 & BAB5452 Yuan, 2015 & - & 19 & c. $2974 \_2 A>G$ & p.Asp992_Gln994del & In-frame \\
\hline 60 & Liu, 2009 & + & 20 & c. $3146 \mathrm{G}>\mathrm{A}$ & p.Arg1049Gln & Missense \\
\hline 61 & Jang, 2015b & - & 21 & c. $3178 \mathrm{G}>\mathrm{A}$ & p.Glu1060Lys & Missense \\
\hline 62 & Jang, 2015b & - & 21 & c. $3178 \mathrm{G}>\mathrm{A}$ & p.Glu1060Lys & Missense \\
\hline 63 & Jang, 2015b & - & 21 & c. $3178 \mathrm{G}>\mathrm{A}$ & p.Glu1060Lys & Missense \\
\hline 64 & Jang $2015^{\mathrm{b}}$ & - & 21 & c. $3178 \mathrm{G}>\mathrm{A}$ & p.Glu1060Lys & Missense \\
\hline 71 & Ansari, 2014 & - & 24 & c.3574_3576del & p.Glu1192del & In-frame \\
\hline \multirow[t]{2}{*}{72} & Baquero, 2014)/Pie, 2016 & + & $1-25$ & $\begin{array}{l}\text { Dup Xp11.22 region } \\
\sim 1.1 \mathrm{Mb}\end{array}$ & & \\
\hline & Present series & & & & & \\
\hline 1 & SMC1ANL001 ${ }^{\mathrm{C}}$ & + & 1 & c. $31 \mathrm{~A}>\mathrm{T}$ & p.Asn11Tyr & Missense \\
\hline 2 & SMC1ANLOO2 $^{\mathrm{C}}$ & + & 2 & c.157dup & p.Thr53AsnfsX34 & Frameshift \\
\hline 3 & SMC1AUSA004 (Deardorff, 2007) & & 2 & c.173_187del & p.Val58_Arg62del & In-frame \\
\hline 4 & SMC1AUSA008 (Deardorff, 2007) & & 3 & c. $397 \mathrm{~T}>\mathrm{G}$ & p.Phe133Val & Missense \\
\hline 5 & SMC1ASPA001 (Deardorff, 2007) & + & 4 & c. $587 \mathrm{G}>\mathrm{A}$ & p.Arg196His & Missense \\
\hline 6 & SMC1AGER003 & + & 4 & c. $587 \mathrm{G}>\mathrm{A}$ & p.Arg196His & Missense \\
\hline 7 & SMC1AFR003 (Borck, 2007) & + & 4 & c. $587 \mathrm{G}>\mathrm{A}$ & p.Arg196His & Missense \\
\hline 8 & SMC1ANL007 ${ }^{\mathrm{C}}$ & + & 5 & c.694G>T & p.Glu232* & Nonsense \\
\hline 9 & SMC1ADEN001 & + & 5 & c.802_804del & p.Lys268del & In-frame \\
\hline 10 & SMC1ASPA002 (Pie, 2010) & + & 5 & c.802_804del & p.Lys268del & In-frame \\
\hline 11 & SMC1AUK008 & + & 5 & c.802_804del & p.Lys268del & In-frame \\
\hline 12 & SMC1AUSA002 (Liu, 2009) & & 5 & c.802_804del & p.Lys268del & In-frame \\
\hline 13 & SMC1AFR005 & + & 6 & c. $919 \mathrm{C}>\mathrm{A}$ & p.His307Asn & Missense \\
\hline 14 & SMC1ADEN002 & + & 6 & c. $920 \mathrm{~A}>\mathrm{T}$ & p.His307Leu & Missense \\
\hline
\end{tabular}


TABLE 5 (Continued)

\begin{tabular}{|c|c|c|c|c|c|c|}
\hline & Index (reference) & $\begin{array}{l}\text { Targeted } \\
\text { analysis }\end{array}$ & Exon & Nucleotide change & Amino acid change & $\begin{array}{l}\text { Coding } \\
\text { effect }\end{array}$ \\
\hline 16 & SMC1AGER001/SMC1AAUSTR001 & + & 9 & c. $1475 A>G$ & p.Gln492Arg & Missense \\
\hline 17 & $\begin{array}{l}\text { SMC1ADEN003 b/SMC1AUSA007 b } \\
\text { (Deardorff, 2007) }\end{array}$ & + & 9 & c. $1487 \mathrm{G}>\mathrm{A}$ & p.Arg496His & Missense \\
\hline 18 & $\begin{array}{l}\text { SMC1ADEN004 b/SMC1AUSA006 b } \\
\text { (Deardorff, 2007) }\end{array}$ & + & 9 & c. $1487 \mathrm{G}>\mathrm{A}$ & p.Arg496His & Missense \\
\hline 20 & SMC1AUK002 (Ansari, 2014) & + & 10 & c.1585_1587 del & p.Lys529del & In-frame \\
\hline 21 & SMC1AUK006 & + & 10 & c. $1607 \mathrm{~A}>\mathrm{T}$ & p.Lys536Met & Missense \\
\hline 22 & SMC1AUSA012 (Wenger, 2016) & - & 10 & c.1636_1638delATT & p.546del & In-frame \\
\hline 23 & SMC1AUSA010 & & 11 & c. $1756 \mathrm{C}>\mathrm{T}$ & p.Arg586Trp & Missense \\
\hline 24 & SMC1AUK004 (Ansari, 2014) & + & 11 & c. $1757 \mathrm{C}>\mathrm{T}$ & p.Arg586Gln & Missense \\
\hline 28 & SMC1ANL014 ${ }^{\mathrm{b}}$ & - & 11 & c. $1904 \mathrm{G}>\mathrm{A}$ & p.Arg635His & Missense \\
\hline 29 & SMC1ANL015 & - & 11 & c.1904G>A & p.Arg635His & Missense \\
\hline 30 & SMC1AGER002/SMC1ASWI001 & + & 13 & c. $2078 \mathrm{G}>\mathrm{A}$ & p.Arg693Gln & Missense \\
\hline 31 & SMC1AFR004 & + & 13 & c.2090_2092dup & p.Glu697_Leu698delinsVal & In-frame \\
\hline 32 & SMC1ANL005 & + & 13 & c. $2095 \mathrm{C}>\mathrm{T}$ & p.Arg699Cys & Missense \\
\hline 33 & SMC1AUSA005 (Deardorff, 2007) & & 13 & c. $2131 \mathrm{C}>\mathrm{T}$ & p.Arg711Trp & Missense \\
\hline 34 & SMC1ASPA003 (Pie, 2010) & + & 13 & c. $2132 \mathrm{G}>\mathrm{A}$ & p.Arg711Gln & Missense \\
\hline 35 & SMC1AITA003 (Gervasini, 2013) & + & 15 & c. $2351 \mathrm{~T}>\mathrm{C}$ & p.lle784Thr & Missense \\
\hline 41 & SMC1ANL008 (Jansen, 2016) & - & 16 & c.2421-?_2562+?del & p.Leu808Argfs*6 & Frameshift \\
\hline 42 & SMC1AUSA011 (Liu, 2009) & & 16 & c. $2446 C>G$ & p.Arg816Gly & Missense \\
\hline 43 & SMC1AFR001 & + & 16 & c. $2455 \mathrm{~A}>\mathrm{C}$ & p.lle819Leu & Missense \\
\hline 44 & SMC1AITA001 $^{\mathrm{b}}$ (Musio, 2006) & + & 16 & c.2493_2495del & p.Asp831_GIn832delinsGlu & In-frame \\
\hline 45 & SMC1AITA002 ${ }^{\mathrm{b}}$ & + & 16 & c.2493_2495del & p.Asp831_GIn832delinsGlu & In-frame \\
\hline 46 & SMC1ANL004 & + & 21 & c. $3145 C>G$ & p.Arg1049Gly & Missense \\
\hline 47 & SMC1AFR0021 (Borck, 2007) & + & 21 & c. $3254 A>G$ & p.Tyr1085Cys & Missense \\
\hline 48 & SMC1AUSA003 (Deardorff, 2007) & & 22 & c. $3364 \mathrm{~T}>\mathrm{C}$ & p.Phe1122Leu & Missense \\
\hline 49 & SMC1ANL003 ${ }^{\mathrm{C}}$ & + & 22 & c. $3367 \mathrm{C}>\mathrm{T}$ & p.Arg1123Trp & Missense \\
\hline 50 & SMC1AITA004 (Gervasini, 2013) & + & 23 & c. $3497 \mathrm{~A}>\mathrm{C}$ & p.Asn1166Thr & Missense \\
\hline 51 & SMC1AUK003 (Ansari, 2014) & + & 24 & c.3574_3576del & p.Glu1192del & In-frame \\
\hline
\end{tabular}

Blank cell indicates that information was unavailable or uncertain.

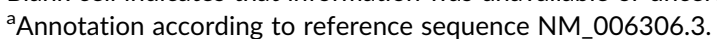

${ }^{\text {b }}$ Familial cases.

${ }^{\mathrm{C}}$ Panel analysis (epilepsy, Rett syndrome); clinically the patients were not suspected as having CdLS, other diagnoses were thought to be more likely.

of the fifth finger occurs less frequently $\left(X^{2} p=0.038\right)$ than in the NIPBL group, and small hands and a proximally placed thumb are also less frequent (statistically not significant). Feeding problems are more frequent in the NIPBL group $\left(X^{2} p=0.0001\right)$, while gastroesophageal reflux disease and constipation are equally common in both groups.
Seizures, however, are more frequent in the SMC1A group $\left(X^{2}\right.$ $p=0.0005$ ), and this is more marked in the group with non-missense SMC1A variants (statistically not significant).

A comparison of cognition and behavior is hampered by the lack of data in a considerable number of individuals in the international 


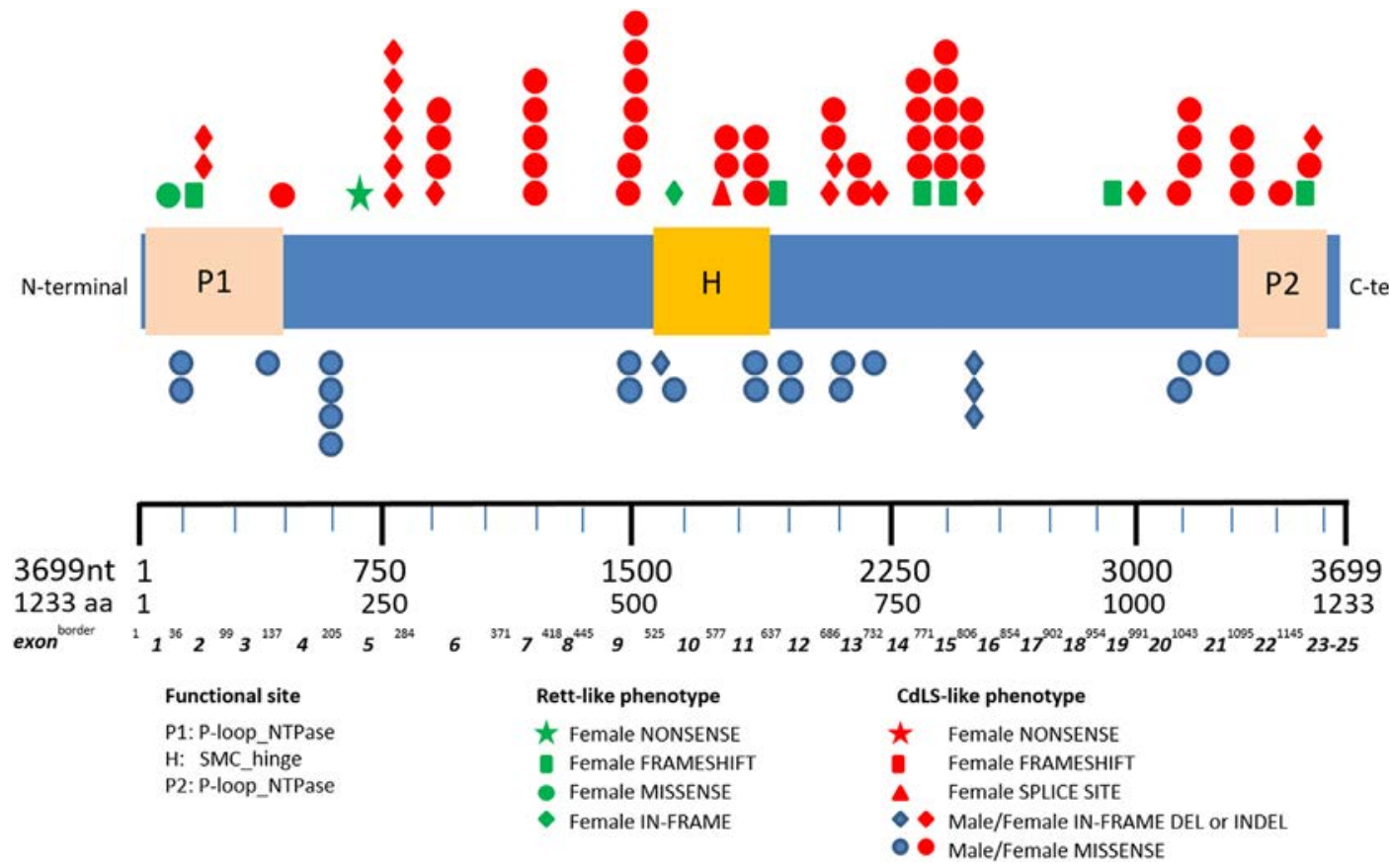

FIGURE 3 Variants in SMC1A reported in literature and in the present series, divided by gender and nature of the mutation. Variants with a Rett-like phenotype are indicated in green. Please note variants are spread evenly over the whole gene, although more mutations are located between the SMC hinge and P-loop NTPase. [Color figure can be viewed at wileyonlinelibrary.com]

SMC1A group and the NIPBL group. The numbers of the in person tested individuals in the Dutch cohort are small and should be used with care. All tested individuals in the Dutch cohort have problems with sensory processing.

In summary, individuals with SMC1A variants show a phenotype that overlaps with CdLS. The frequencies of some signs and symptoms are lower than in individuals with NIPBL mutations. Major phenotypic distinctions are the absence of limb reduction defects and increased prevalence of seizures in the SMC1A group. Another main difference is self-injurious behavior which is much more frequent and more severe in the NIPBL group.

The Dutch SMC1A group likely covers all individuals with SMC1A variants currently known in the Netherlands. The group includes both patients who were clinically diagnosed with CdLS, and those in whom a variant was unexpectedly detected through exome sequencing. We recognize two groups in the Dutch cohort: individuals with a phenotype similar to CdLS, and a group with an epileptic encephalopathy. Individuals with an epileptic encephalopathy have been previously reported as well (de Ligt et al., 2012; Fieremans et al., 2016; Gilissen et al., 2014; Goldstein et al., 2015; Hansen et al., 2013; Jang et al., 2015; Jansen et al., 2016; Lebrun et al., 2015; Tzschach et al., 2015). In the Dutch cohort 5 of 13 (38\%) individuals had an epileptic encephalopathy. In evaluating these female patients we were struck by the resemblance to females with progressed stages in Rett syndrome and their typical impaired ability to make contact and interact. All have severe or profound intellectual disabilities and four of the five Dutch females (five of the seven females of the total Rett-like group) showed hand movements such as "hand wringing" (Table 4). Regression has been reported in literature (Goldstein et al., 2015;
Jansen et al., 2016) and is reported here in three of the five females (Table 4). In two other females epilepsy and developmental delay manifested at such young age that this may have masked any sign of regression. Other characteristics of the individuals with an epileptic encephalopathy were a lower birth weight and a lower postnatal height compared to the others in the SMC1A group. According to severity classification terminology (classical, mild, possible CdLS) their faces were assessed as possible CdLS, except in the youngest female who was assessed as mild CdLS. No face morphology was rated as classical CdLS. There is anecdotal evidence that individuals with SMC1A variants have a rounder face compared to individuals with NIPBL variants and this seems more marked in individuals with a Rettlike phenotype than in individuals with SMC1A variants in general (Figure 1).

We considered a cluster analysis of signs and symptoms to determine which set of phenotypical characteristics is more similar to each other in one sub-phenotype than in another, but the total numbers were too small to allow for meaningful results.

The exact phenotype of the subgroup of individuals with SMC1A variants with an epileptic encephalopathy and severe-profound intellectual disability has not emerged yet, but it is likely that more individuals will be recognized as exome sequencing is increasingly used worldwide. This may allow better insight whether the phenotypes are truly separate or rather ends of a spectrum. In the Netherlands, five of the thirteen patients known with SMC1A pathological variants have an epileptic encephalopathy phenotype (Table 4). Possibly this phenotype is much more common than anticipated. The mutations of individuals with the epileptic encephalopathy are spread all over the gene and a clear correlation does not 
appear (Figure 3). All mutations are nonsense or frameshift mutations except one missense mutation (SMC1ANL001; Table 4), located at the first part of exon 1, in which functional studies have indicated it to cause a loss of function as well (Dr. Erwan Watrin, personal communication, 2017). To date there is no known exon 8 SMC1A mutation.

SMC1A incompletely escapes X-inactivation (Gervasini et al., 2013; Goldstein et al., 2015; Limongelli et al., 2010; Liu, Feldman, et al., 2009; Mannini et al., 2010; Tzschach et al., 2015). Since, there is no altered level of SMC1A transcripts and mutant proteins maintain a residual function (Liu, Feldman, et al., 2009), and a dominant negative effect is considered the pathogenic mechanism in females with a SMC1A variant, the level of allelic preferential expression might be one of the factors contributing to the wide phenotypic variability observed in these patients (Parenti et al., 2014). In the present study there is a remarkably distorted ratio of males and females with a SMC1A variant for non-missense variants. The small number of males with nonmissense variants had in frame deletions. This seems to indicate that other types of mutations are not tolerated in males, likely leading to early miscarriages, and explaining the distorted gender ratio. We evaluated spontaneous abortions reported by the families: 22/49 (45\%) families reported no known miscarriages, 3/49 (6\%) families experienced a single miscarriage, and one (2\%) family (with mutation c.3145C>G; p.Arg1049Gly) had six miscarriages for which no cause could be found (no data on the other 24 families). Although, normal values for spontaneous miscarriages in the various populations are not available it seems likely the miscarriage rate in the families in total is not increased.

The present study has several limitations. First, the CdLS-like phenotype in the SMC1A group is very likely overestimated due to acquisition bias, as patients suspected to have CdLS were referred to CdLS specialists, whom we specifically invited to participate in the study. The specialists confirmed that all included individuals with SMC1A variants were suspected to have CdLS. We contacted the UK 100,000 genome project in order to obtain an estimate of the frequency of SMC1A mutations in a large group of individuals, but at present such a detailed question cannot be answered yet (Richard Scott, personal communication, 2016). Therefore, the phenotype presented here is mainly representative of the phenotype similar to CdLS and less of the epileptic encephalopathy "Rett-like" phenotype. Although, numbers are small, prevalences of these two subphenotype groups in the Netherlands indicate that the latter phenotype might occur even more frequently than the former.

Furthermore, cross sectional data collection using binary categories to describe features hampers the reporting of gradations and changes over time. Moreover, as the somatic questionnaire was extensive, we had to deal with missing data from several patients. These experiences underline the importance of using standardized, longitudinal databases (Baas et al., 2015). Performing research with a large group of collaborating physicians may have influenced phenotype evaluations, especially with respect to facial morphology. As differences between the presently in person examined patients and patients evaluated by a group of others were small, it seems unlikely that this has played a major role.
Data on cognitive and adaptive functioning and the measures used are often missing in the medical file, and if these are available, different developmental and behavioral assessment instruments are typically used. We strongly advocate direct and indirect assessments of cognitive and adaptive functioning and behavior of affected individuals, performed by behavioral scientists, and that these always form an integrated part of an interdisciplinary evaluation.

We conclude that SMC1A variants can result in different phenotypes: a phenotype that overlaps with mild manifestations of CdLS and one that overlaps with Rett syndrome. Likely the increasing use of exome and genome sequencing will lead more frequently to identification of SMC1A variants in individuals not clinically suspected of CdLS. Large series of individuals recognized in this way should facilitate cluster analyses that may allow either separating distinct SMC1A phenotypes or merging these into one spectrum. Such better insights will allow better genetic counseling, allow health care professionals to answer the primary question of parents what it means if a SMC1A variant is found in their child.

\section{ACKNOWLEDGMENTS}

We are exceptionally grateful to the patients with SMC1A variants and their families who participated in this study. We are very grateful to the Prinsenstichting for funding in part the work of $\mathrm{SH}$, and to the Dutch and Polish CdLS Associations for cooperation in the development of detailed clinical data NIPBL positive patients. We sincerely thank Dr Alina Kuzniacka and Natalia Krawczyńska from Department of Biology and Genetics, Medical University in Gdańsk for molecular analysis. This work was supported by National Institutes of Health Grants UMO-2014/15/B/NZ5/03503. This work was supported by the Spanish Ministry of Health - ISCIII, Fondo de Investigación Sanitaria (FIS) [Ref: PI15/00707] and the Diputación General de Aragón [Grupo Consolidado B20], European Social Fund ("Construyendo Europa desde Aragón") to FJRF and JPJ. This work was funded by the German Federal Ministry of Education and Research (BMBF, CHROMATIN-Net) to FJK and GG-K. We dedicate this manuscript to the excellent clinician and caregiver, a colleague and a friend, Ton van Essen, who died during the preparation of the manuscript.

\section{REFERENCES}

Ansari, M., Poke, G., Ferry, Q., Williamson, K., Aldridge, R., Meynert, A. M., ... FitzPatrick, D. R. (2014). Genetic heterogeneity in Cornelia de Lange syndrome (CdLS) and CdLS-like phenotypes with observed and predicted levels of mosaicism. Journal of Medical Genetics, 51, 659-668.

Baas, M., Huisman, S., van Heukelingen, J., Koekkoek, G., Laan, H. W., \& Hennekam, R. C. (2015). Building treasures for rare disorders. European Journal of Medical Genetics, 58, 11-13.

Basel-Vanagaite, L., Wolf, L., Orin, M., Larizza, L., Gervasini, C., Krantz, I. D., \& Deardoff, M. A. (2016). Recognition of the Cornelia de Lange syndrome phenotype with facial dysmorphology novel analysis. Clinical Genetics, 89, 557-563.

Bhuiyan, Z. A., Klein, M., Hammond, P., van Haeringen, A., Mannens, M. M. A. M., Van Berckelaer-Onnes, I., \& Hennekam, R. C. M. (2006). Genotype-phenotype correlations of 39 patients with Cornelia De 
Lange syndrome: The Dutch experience. Journal of Medical Genetics, 43 , 568-575.

Borck, G., Zarhrate, M., Bonnefont, J. P., Munnich, A., Cormier-Daire, V., \& Colleaux, L. (2007). Incidence and clinical features of X-linked Cornelia de Lange syndrome due to SMC1L1 mutations. Human Mutation, 28, 205-206.

Chatfield, K. C., Schrier, S. A., Li, J., Clark, D., Kaur, M., Kline, A. D., ... Krantz, I. D. (2012). Congenital heart disease in Cornelia de Lange syndrome: Phenotype and genotype analysis. American Journal of Medical Genetics Part A, 158A(1), 2499-2505.

de Ligt, J., Willemsen, M. H., van Bon, B. W. M., Kleefstra, T., Yntema, H. G., Kroes, T., ... Vissers, L. E. L. M. (2012). Diagnostic exome sequencing in persons with severe intellectual disability. N Engl J Med, 367, 1921-1929.

Deardorff, M. A., Kaur, M., Yaeger, D., Rampuria, A., Korolev, S., Pie, J., .. . Krantz, I. D. (2007). Mutations in cohesin complex members SMC3 and SMC1A cause a mild variant of Cornelia de Lange syndrome with predominant mental retardation. American Journal of Human Genetics, 80, 485-494.

Fieremans, N., Van Esch, H., Holvoet, M., Van Goethem, G., Devriendt, K., Rosello, M., .. . Froyen, G. (2016). Identification of intellectual disability genes in female patients with a skewed $\mathrm{x}$ inactivation pattern. Human Mutation, 37, 804-811.

Gervasini, C., Russo, S., Cereda, A., Parenti, I., Masciadri, M., Azzollini, J., . . . Larizza, L. (2013). Cornelia de Lange individuals with new and recurrent SMC1A mutations enhance delineation of mutation repertoire and phenotypic spectrum. American Journal of Medical Genetics Part A, 161A(1), 2909-2919.

Gilissen, C., Hehir-Kwa, J. Y., Thung, D. T., van de Vorst, M., van Bon, B. W. M., Willemsen, M. H., ... Veltman, J. A. (2014). Genome sequencing identifies major causes of severe intellectual disability. Nature, 511, 344-347.

Gillis, L. A., McCallum, J., Kaur, M., DeScipio, C., Yaeger, D., Mariani, A., ... Krantz, I. D. (2004). NIPBL mutational analysis in 120 individuals with Cornelia de Lange syndrome and evaluation of genotype-phenotype correlations. American Journal of Human Genetics, 75, 610-623.

Goldstein, J. H., Tim-Aroon, T., Shieh, J., Merrill, M., Deeb, K. K., Zhang, S., ... Bedoyan, J. K. (2015). Novel SMC1A frameshift mutations in children with developmental delay and epilepsy. European Journal of Medical Genetics, 58, 562-568.

Hansen, J., Mohr, J., Burki, S., \& Lemke, J. R. (2013). A case of cohesinopathy with a novel de-novo SMC1A splice site mutation. Clinical Dysmorphology, 22, 143-145.

Hoppman-Chaney, N., Jang, J. S., Jen, J., Babovic-Vuksanovic, D., \& Hodge, J. C. (2012). In-frame multi-exon deletion of SMC1A in a severely affected female with Cornelia de Lange Syndrome. American Journal of Medical Genetics Part A, 158A, 193-198.

Huisman, S. A., Redeker, E. J., Maas, S. M., Mannens, M. M., \& Hennekam, R. C. (2013). High rate of mosaicism in individuals with Cornelia de Lange syndrome. Journal of Medical Genetics, 50, 339-344.

Huisman, S., Mulder, P., Kuijk, J., Kerstholt, M., Van Eeghen, A., Leenders, A., ... Hennekam, R. (2017) Self-Injurious Behavior, Neuroscience \& Biobehavioral Reviews, (in press).

Jang, M. A., Lee, C. W., Kim, J. K., \& Ki, C. S. (2015). Novel pathogenic variant (c.3178G>A) in the SMC1A gene in a family with Cornelia de Lange syndrome identified by exome sequencing. Annals of Laboratory Medicine, 35, 639-642.

Jansen, S., Kleefstra, T., Willemsen, M. H., de Vries, P., Pfundt, R., HehirKwa, J. Y., ... Vissers, L. E. (2016). De novo loss-of-function mutations in X-linked SMC1A cause severe ID and therapy resistant epilepsy in females: Expanding the phenotypic spectrum. Clinical Genetics, 90, 413-419.
Jeffery, C. J. (2014). An introduction to protein moonlighting. Biochemical Society Transactions, 42, 1679-1683.

Kawauchi, S., Calof, A. L., Santos, R., Lopez-Burks, M. E., Young, C. M., Hoang, M. P., ... Lander, A. D. (2009). Multiple organ system defects and transcriptional dysregulation in the Nipbl(+/-) mouse, a model of Cornelia de Lange Syndrome. PLoS Genetics 5:e1000650.

Kawauchi, S., Santos, R., Muto, A., Lopez-Burks, M. E., Schilling, T. F., Lander, A. D., \& Calof, A. L. (2016). Using mouse and zebrafish models to understand the etiology of developmental defects in Cornelia de Lange Syndrome. American Journal of Medical Genetics Part C, Seminars in Medical Genetics, 172C, 138-145.

Kline, A. D., Krantz, I. D., Sommer, A., Kliewer, M., Jackson, L. G., FitzPatrick, D. R., ... Selicorni, A. (2008). Cornelia de lange syndrome: Clinical review, diagnostic and scoring systems, and anticipatory guidance. American Journal of Medical Genetics Part A, 146A, 2713-2713.

Krantz, I. D., McCallum, J., DeScipio, C., Kaur, M., Gillis, L. A., Yaeger, D., . . Jackson, L. G. (2004). Cornelia de Lange syndrome is caused by mutations in NIPBL, the human homolog of Drosophila melanogaster Nipped-B. Nature Genetics, 36, 631-635.

Kuzniacka, A., Wierzba, J., Ratajska, M., Lipska, B. S., Koczkowska, M., Malinowska, M., \& Limon, J. (2013). Spectrum of NIPBL gene mutations in Polish patients with Cornelia de Lange syndrome. Journal of Applied Genetics, 54, 249-249.

Lebrun, N., Lebon, S., Jeannet, P. Y., Jacquemont, S., Billuart, P., \& Bienvenu, T. (2015). Early-onset encephalopathy with epilepsy associated with a novel splice site mutation in SMC1A. American Journal of Medical Genetics Part A, 167A(1), 3076-3081.

Limongelli, G., Russo, S., Digilio, M. C., Masciadri, M., Pacileo, G., Fratta, F., ... Larizza, L. (2010). Hypertrophic cardiomyopathy in a girl with Cornelia de Lange syndrome due to mutation in SMC1A. American Journal of Medical Genetics Part A, 152A(1), 2127-2129.

Liu, J., Feldman, R., Zhang, Z., Deardorff, M. A., Haverfield, E. V., Kaur, M., ... Krantz, I. D. (2009). SMC1A expression and mechanism of pathogenicity in probands with X-Linked Cornelia de Lange syndrome. Human Mutation, 30, 1535-1542.

Liu, J., Zhang, Z., Bando, M., Itoh, T., Deardorff, M. A., Clark, D., ... Krantz, I. D. (2009). Transcriptional dysregulation in NIPBL and cohesin mutant human cells. PLoS Biology 7, e1000119.

Liu, J. L., \& Krantz, I. D. (2008). Cohesin and human disease. Annual Review of Genomics and Human Genetics, 9, 303-320.

Luzzani, S., Macchini, F., Valade, A., Milani, D., \& Selicorni, A. (2003). Gastroesophageal reflux and Cornelia de Lange syndrome: Typical and atypical symptoms. American Journal of Medical Genetics Part A, 119A, 283-287.

Mannini, L., Liu, J., Krantz, I. D., \& Musio, A. (2010). Spectrum and consequences of SMC1A mutations: The unexpected involvement of a core component of cohesin in human disease. Human Mutation, 31, 5-10.

Moss, J., Howlin, P., Magiati, I., \& Oliver, C. (2012). Characteristics of autism spectrum disorder in Cornelia de Lange syndrome. Journal of Child Psychology and Psychiatry, 53, 883-891.

Mulder, P. A., Huisman, S. A., Hennekam, R. C., Oliver, C., van Balkom, I. D., \& Piening, S. (2016). Behaviour in Cornelia de Lange syndrome: A systematic review. Developmental Medicine \& Child Neurology, 59, 361-366. https://doi.org/10.1111/dmcn.13361

Musio, A., Selicorni, A., Focarelli, M. L., Gervasini, C., Milani, D., Russo, S., . . . Larizza, L. (2006). X-linked Cornelia de Lange syndrome owing to SMC1L1 mutations. Nature Genetics, 38, 528-530.

Oliver, C., Sloneem, J., Hall, S., \& Arron, K. (2009). Self-injurious behaviour in cornelia de lange syndrome: 1 . Prevalence and phenomenology. Journal of Intellectual Disability Research, 53, 575-589. 
Parenti, I., Rovina, D., Masciadri, M., Cereda, A., Azzollini, J., Picinelli, C., .. . Larizza, L. (2014). Overall and allele-specific expression of the SMC1A gene in female Cornelia de Lange syndrome patients and healthy controls. Epigenetics, 9, 973-979.

Pie, J., Gil-Rodriguez, M. C., Ciero, M., Lopez-Vinas, E., Ribate, M. P., Arnedo, M., ... Ramos, F. J. (2010). Mutations and variants in the cohesion factor genes NIPBL, SMC1A, and SMC3 in a cohort of 30 unrelated patients with Cornelia de Lange syndrome. American Journal of Medical Genetics Part A, 152A, 924-929.

Pie, J., Puisac, B., Hernandez-Marcos, M., Teresa-Rodrigo, M. E., GilRodriguez, M., Baquero-Montoya, C., ... Ramos, F. J. (2016). Special cases in cornelia de lange syndrome: The spanish experience. American Journal of Medical Genetics Part C, Seminars in Medical Genetics, 172C, 198-205.

Remeseiro, S., Cuadrado, A., \& Losada, A. (2013). Cohesin in development and disease. Development, 140, 3715-3718.

Rohatgi, S., Clark, D., Kline, A. D., Jackson, L. G., Pie, J., Siu, V., .. . Deardorff, M. A. (2010). Facial diagnosis of mild and variant CdLS: Insights from a dysmorphologist survey. American Journal of Medical Genetics Part A, 152A(1), 1641-1653.

Tonkin, E. T., Wang, T. J., Lisgo, S., Bamshad, M. J., \& Strachan, T. (2004). NIPBL, encoding a homolog of fungal Scc2-type sister chromatid cohesion proteins and fly Nipped-B, is mutated in Cornelia de Lange syndrome. Nature Genetics, 36, 636-641.

Tzschach, A., Grasshoff, U., Beck-Woedl, S., Dufke, C., Bauer, C., Kehrer, M., ... Bauer, P. (2015). Next-generation sequencing in X-linked intellectual disability. European Journal of Human Genetics, 23, 1513-1518.

Vega, H., Waisfisz, Q., Gordillo, M., Sakai, N., Yanagihara, I., Yamada, M., .. . Joenje, H. (2005). Roberts syndrome is caused by mutations in ESCO2, a human homolog of yeast ECO1 that is essential for the establishment of sister chromatid cohesion. Nature Genetics, 37, 468-470.

Wenger, T. L., Chow, P., Randle, S. C., Rosen, A., Birgfeld, C., Wrede, J., ... Albers, E. (2016). Novel findings of left ventricular non-compaction cardiomyopathy, microform cleft lip and poor vision in patient with SMC1Aassociated Cornelia de Lange syndrome. American Journal of Medical Genetics Part A, 9999A, 1-7.

Yan, J., Saifi, G. M., Wierzba, T. H., Withers, M., Bien-Willner, G. A., Limon, J., ... Wierzba, J. (2006). Mutational and genotype-phenotype correlation analyses in 28 Polish patients with Cornelia de Lange syndrome. American Journal of Medical Genetics Part A, 140A, 1531-1541.

Yuan, B., Pehlivan, D., Karaca, E., Patel, N., Charng, W. L., Gambin, T., ... Lupski, J. R. (2015). Global transcriptional disturbances underlie Cornelia de Lange syndrome and related phenotypes. Journal of Clinical Investigation, 125, 636-651.

\section{SUPPORTING INFORMATION}

Additional Supporting Information may be found online in the supporting information tab for this article.

How to cite this article: Huisman S, Mulder PA, Redeker E, et al. Phenotypes and genotypes in individuals with SMC1A variants. Am J Med Genet Part A. 2017;9999:1-18.

https://doi.org/10.1002/ajmg.a.38279 